\title{
The assessment of invasive alien plant species removal programs using remote sensing and GIS in two selected reserves in the eThekwini Municipality, KwaZulu-Natal.
}

\author{
Yusuf Adam $^{\mathrm{a}}$, Njoya S Ngetara ${ }^{\mathrm{a}}$, Syd Ramdhani ${ }^{\mathrm{b}}$
}

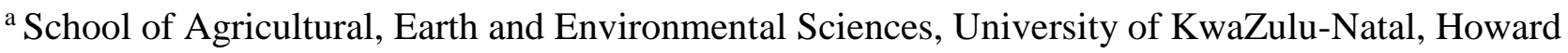
College, Durban, South Africa, Email: yusufadam12@gmail.com

${ }^{\mathrm{b}}$ School of Life Sciences, University of KwaZulu-Natal, Westville Campus, Westville, Durban, South Africa
\end{abstract}

DOI: http://dx.doi.org/10.4314/sajg.v6il.6

\begin{abstract}
The occupation of natural environments by invasive alien plant species (IAPs) are a growing threat to ecosystems. This has resulted in the creation of government-based initiatives to mitigate invasion, however, there has been little progress towards assessing these initiatives. Remote sensing is a commonly used tool in the detection of IAPs; even so, there has also been little research towards its use as a tool to assess mitigation efforts. This study aims to assess the clearing initiatives of three IAPs which are Acacia podalyriifolia, Chromolaena odorata and Litsea glutinosa in two nature reserves (Paradise Valley and Roosfontein) within the eThekwini Municipality, KwaZulu-Natal, (South Africa) using remote sensing. To achieve this aim, image classification using the Maximum Likelihood classifier was performed on both sites before and after clearing to compare density, distribution and area cover. All species were successfully detected in both reserves in both the 2010 and 2015 imagery except L. glutinosa in the Paradise Valley Nature Reserve in 2010. User's and producer's accuracy for A. podalyriifolia and C. odorata (Paradise Valley) and C. odorata L. glutinosa (Roosfontein) were more than 70\% in both 2010 and 2015, which is above agreed standards. The occurrence and area cover of all species in both reserves decreased substantially except L. glutinosa in Paradise Valley Nature Reserve, which experienced only a slight decrease in area cover. The results indicate that remote sensing is a suitable tool for the assessment of IAP removal strategies. Further research should consider early detection of IAPs to prevent spread.
\end{abstract}

Key words: Invasive alien plant species, remote sensing, species detection, removal assessment

\section{Introduction}

Invasive alien plants species are those that are introduced to areas outside of their indigenous ranges, become established and thereafter usurp indigenous species (Kannan, Shackleton, \& Uma Shaanker, 2013). These species affect human health, agriculture, forestry and biodiversity 
(Richardson \& van Wilgen, 2004). They impact on ecosystems by displacing indigenous vegetation and change ecosystem functions (Loh \& Daehler, 2008). This leads to a reduction in the genetic variation of an environment due to localised extinction of endemic species. Invasion also has subtle socio-economic impacts such as interrupting the supply of ecosystem goods and reducing resource availability for indigenous species (Vilà et al., 2010).

Interest in the field of IAPs is growing with an increase in funds dedicated to dealing with invasion, however, IAPs continue to expand (D’Antonio, Jackson, Horvitz, \& Hedberg, 2004). The control of IAPs involve both reducing the introduction of new species and the management of current IAPs (van Wilgen et al., 2012). Therefore regular monitoring of IAPs is required to manage invasion effectively and efficiently, which in turn requires methods that can detect IAPs rapidly and precisely (Müllerová, Pergl, \& Pyšek, 2013). Field surveys can be used to map IAPs, however, these are inefficient over larger areas (Malahlela, Cho, \& Mutanga, 2015). Aerial photographs have been successful to an extent as they are able to detect IAPs which are unique to other surrounding vegetation (Lass et al., 2005). Remote sensing is an ideal tool for detecting IAPs as it can be employed in a variety of habitats (Lass et al., 2005), map species over large extents (Calviño-Cancela, Méndez-Rial, Reguera-Salgado, \& Martín-Herrero, 2014) and detect vegetation at species level (Mutanga, van Aardt, \& Kumar, 2009).

Individual IAPs can be detected using remote sensing due to variations in their reflectance patterns in certain portions of the electromagnetic spectrum (Rocchini et al., 2015). Multispectral imagery can be successfully applied to map IAPs, however, these species would need to have unique reflectance patterns when compared to indigenous species (Cuneo, Jacobson, \& Leishman, 2009). Remote sensing has been successfully applied in mapping invasive trees and shrubs. Herbaceous species can also be detected if they form dense stands and are spectrally distinct from other surrounding species within their environment (Müllerová et al., 2013).

In South Africa, IAP intervention strategies have been employed nationally and have mitigated the impacts of invasion (van Wilgen et al., 2012). Despite the application of these removal strategies, the abundance and impact of IAPs is still increasing (Müllerová et al., 2013). The Working for Water program is a national program aimed at the control of IAPs initiated by the South African government (van Wilgen et al., 2012). This program was initiated in 1995 and between 1995 and in 2007 cleared 1.6 million ha of IAPs at the cost of ZAR 3.2 billion. The program employs chemical, biological and physical removal strategies (van Wilgen et al., 2012) and is one of the largest IAPs removal initiatives globally (Richardson \& van Wilgen, 2004). Without these clearing initiatives, areas that experienced $22 \%$ invasion could become completely invaded within three decades (Le Maitre et al., 2002). One of the major concerns with these clearing programs is the lack of an effective system for evaluating and monitoring the success of removal (van Wilgen et al., 2012).

Protected areas are a corner stone in terms of conservation and are designed to reduce biodiversity loss, however, these areas need to be maintained. The detection of changes in the abundance of plant 
species within these areas will aid in maintenance (Nagendra et al., 2013). Also in smaller reserves the density and abundance of IAPs are important factors to consider (Richardson \& van Wilgen, 2004) to aid in mitigation. Change detection examines the differences between images of the same area at different time periods (Coppin \& Bauer, 2009). Remote sensing is a powerful tool used for change detection (Kerr \& Ostrovsky, 2003), due to the frequent return time of satellites (Singh, 1989), also referred to as high temporal resolution (Bradley, 2014).

This study aims to investigate the use of remote sensing for mapping IAPs and assessing clearing programs of three IAPs in two urban nature reserves within the eThekwini Municipality.

\section{Methods}

\subsection{Study site}

The Paradise Valley $\left(29.83^{\circ} \mathrm{S}, 30.89^{\circ} \mathrm{E}\right)$ and Roosfontein $\left(29.86^{\circ} \mathrm{S}, 30.92^{\circ} \mathrm{E}\right)$ nature reserves (Figure 1) are located in the eThekwini Municipality just west of the city of Durban (KwaZulu-Natal, South Africa), within close proximity to one another. Both reserves are roughly $300 \mathrm{ha}$ in size and include grasslands, thicket and forest vegetation. This region receives an average of $1010 \mathrm{~mm}$ of rainfall annually with a majority of the rainfall occurring between November and March. The average annual temperature is $20.5^{\circ} \mathrm{C}$ (Preston-Whyte, 1980). The Environmental Planning and Climate Protection Department (EPCPD) in conjunction with Wildlife and Environmental Society of South Africa (WESSA) initiated clearing programs in the Paradise Valley and Roosfontein nature reserves in 2011 and 2010, respectively. 

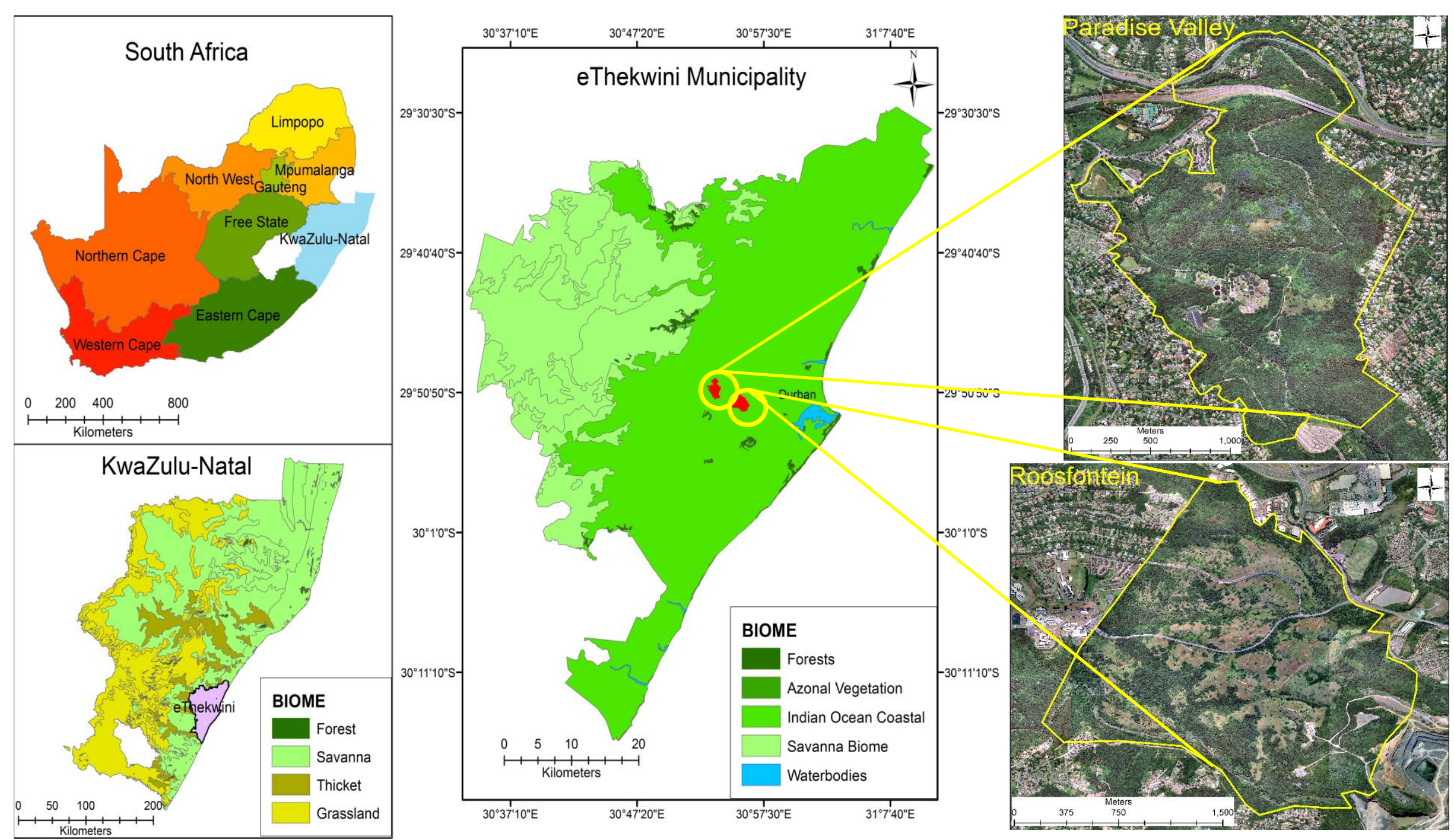

Figure 1. Location map of the two study sites (Paradise Valley and Roosfontein nature reserves) 


\subsection{Field data collection and image processing}

Field data for the classification of IAPs was supplied by WESSA. This data was created in spring. Therefore WorldView-2 (4 band) images of both 2010 and 2015 were purchased from SANSA (South African National Space Agency) for September of their respective years to be consistent. The time of image acquisition is crucial as species differ spectrally due to seasonal variations (Lass et al., 2005). Selecting images for the same time of the year will reduce sun angle distortions and spectral distortions caused by phenotypic variation of species (Mas, 1999). These images were then pan sharpened using a subtractive resolution merge, with a sharpening centre value of 17 , a pan contribution weight of 1 as these were 4 band images (Zhang \& Mishra, 2012).

One of issues related to satellite image acquisition is cloud cover (Kerr \& Ostrovsky, 2003). The 2015 imagery had a significant amount of cloud cover (14.6\%) over the Roosfontein site. Cloud correction was done using ATCOR 3 extension for ERDAS Imagine 2015. Initially solar zenith and solar azimuth were calculated and thereafter a DEM of the study area was created in ArcMap using 2m contours; all of these were inputted into ATCOR 3 as part of the haze removal process. The correction module was run with a 35 cloud threshold and a 9 water threshold to remove haze. A haze reduction tool from ERDAS was thereafter applied to further sharpen the image. The DN (digital numbers) of both the 2010 and 2015 images were then converted to top of atmosphere reflectance values by a conversion model created using the spatial model editor in ERDAS Imagine (Miao, Patil, Heaton, \& Tracy, 2011).

Three species (A. podalyriifolia, C. odorata and L. glutinosa) in the Paradise Valley Nature Reserve and two species (C. odorata and L. glutinosa) in the Roosfontein Nature Reserve were classified for the purpose of this study. Only two species were classified in the Roosfontein Nature Reserve as A. podalyriifolia occurred in negligible quantities. Training sites were created using 60 samples with 12 samples representing each IAP in each reserve. These were developed by digitizing polygons of each IAP on high resolution 2010 WorldView-2 imagery with the aid of field data provided by WESSA. These polygons were then imported into ERDAS imagine where spectra was extracted to be used for image classification. Pre-clearing (2010) imagery was used for training site development, as post clearing (2015) imagery did not contain adequate monotypic stands of the target IAPs for spectral signature development.

\subsection{Image classification}

A Maximum Likelihood classifier was used to classify imagery of both sites from 2010 and 2015 to detect the selected IAPs. In comparison to other classifiers (parallelepiped, unsupervised and the spectral angle mapper) the Maximum Likelihood classifier resulted in the highest classification accuracy (Doody, Lewis, Benyon, \& Byrne, 2014). The Maximum Likelihood classifier uses mean reflectance to determine the probability of a pixel belonging to 
a certain class (Lass et al., 2005). The threshold for the classification of the imagery was defined with 2 degrees of freedom and a 0.025 confidence level. Thereafter a post classification comparison approach was used where the 2010 and 2015 individually classified images were compared (Singh, 1989).

Verification of the 2010 classified results was conducted by overlaying sampled preclearing IAP locations provided by WESSA on WorldView-2 imagery. One hundred (100) such sampled points were imported into ERDAS and each assigned a reference value for accuracy assessment (Stuckenberg, Münch, \& van Niekerk, 2014). Accuracy verification of the 2015 imagery was determined using points obtained in the field (Sarma et al., 2008). This was achieved by purposive random sampling; 10 locations were selected for each species at each study area and were given priority based on ease of site access (Underwood, Ustin, \& DiPietro, 2003). In the Paradise Valley Nature Reserve L. glutinosa was not sampled as in both the 2010 and 2015 classification results this species occupied most of the map with no change in distribution between the pre-clearance (2010) and post clearance (2015) classification.

An accuracy assessment was run on the 2010 and 2015 imageries for both sites, defining the overall accuracy, user's accuracy, producer's accuracy and the Kappa statistic. For a classification to be regarded as successful an overall accuracy of $85 \%$ is required and for individual species, accuracies should be $70 \%$ and over (Everitt, Yang, Fletcher, \& Deloach, 2008). Kappa values from 0 to 0.4 are regarded as a moderate agreement, with 0.4 to 0.8 as a substantial agreement and above 0.8 an excellent agreement. Root Mean Square Error (RMSE) and Mean Absolute Error (MAE) were also calculated, these are similar indices which determine the performance of a classification, with values closer to zero indicating better performance (Kumar \& Sahoo, 2012). Multiple accuracy assessments indices were calculated as recommended due to each index having its own strengths and weaknesses (Foody, 2002).

\subsection{Spatial distribution and density of IAPs}

Distribution and density maps were created for both sites using the fishnet grid method (Vieira, Finn \& Bradley, 2014) in ArcMap 10.2 using point density analysis (Eck, Chainey, Cameron, Leitner, \& Wilson, 2005; van den Berg, Kotze \& Beukes, 2014). Post image classification, pixels representing each of the target IAPs were converted into separate point vector files. Thereafter grids representing quadrats measuring $5 \mathrm{~m}$ by $5 \mathrm{~m}$ were created (Johansen, Phinn \& Witte, 2010). These quadrats were used in conjunction with the species point vector files to create spatial distribution and density maps of each IAPs. Species densities were calculated as percentage cover per quadrat (Eck et al., 2005), using the equation: 


$$
d=\left(\frac{n}{a}\right) \times 100
$$

$\mathrm{d}=$ density

$\mathrm{n}=$ number of points that represent an IAP within the quadrat

$\mathrm{a}=$ area of the grid or quadrat occupied by IAP

The resulting maps did not adequately reveal the densities of the selected IAPs due to the small quadrat size. In order to reveal these densities, different fishnet sizes (grid sizes) were tested and a quadrat size of $50 \mathrm{~m}$ by $50 \mathrm{~m}$, proved adequate for revealing IAP densities pre-and post-clearance that corroborated image classification accuracies.

Thereafter IAP densities were categorised into low (4\% - 33\%), moderate (34\% - 66\%) and high density (67\% - 100\%) (van den Berg et al., 2014), while density below 4\% were considered errors of commission (Borak, 1999). Densities were represented by intensity of quadrat colour; where quadrats with higher colour intensity indicate a higher species density. The area coverage of each IAP before and after clearing was calculated for both sites to aid in change detection and determine the success of IAPs removal programs.

\section{Results}

Overall classification accuracies in the year 2010 for Paradise Valley Nature Reserve (72\%) and Roosfontein Nature Reserve (82\%) (Table 1) were unsuccessful considering the $85 \%$ acceptable threshold for overall accuracy (Everitt et al., 2008). However, the RMSE and MAE values in 2010 for Roosfontein Nature Reserve were lower than the Paradise Valley Nature Reserve values, indicating higher classification accuracy. Overall classification accuracy in the year 2015 was equal to and above the standard threshold for both study sites with accuracies of $85 \%$ and above, and very low RMSE and MAE values.

Table 1. Overall accuracy of the Maximum Likelihood classifier performed on both nature reserves in 2010 and 2015

\begin{tabular}{llllll}
\hline & Year & $\begin{array}{l}\text { Overall } \\
(\boldsymbol{\%})\end{array}$ & accuracy Overall Kappa MAE & RMSE \\
\hline \multirow{2}{*}{ Paradise Valley } & 2010 & 72.33 & 0.6272 & 27.67 & 28.63 \\
& 2015 & 100 & 1 & 0 & 0 \\
\multirow{3}{*}{ Roosfontein } & 2010 & 81.5 & 0.6864 & 18.5 & 18.51 \\
& 2015 & 85 & 0.7 & 1.5 & 1.58 \\
\hline
\end{tabular}

Individual user's and producer's accuracies above $70 \%$ have been recommended for successful image classification (Everitt et al., 2008). In the Paradise Valley Nature Reserve $A$. podalyriifolia and C. odorata were both successfully detected in 2010 imagery with user's and producer's accuracies above $70 \%$ (Table 2), while L. glutinosa, with a 63\%, represented the 
lowest classified species (Foody, 2002). C. odorata and L. glutinosa were successfully detected in the Roosfontein Nature Reserve with user's and producer's accuracies higher than $70 \%$. Individual Kappa values for all species in both reserves were excellent (above 0.8 ) besides $L$. glutinosa in the Paradise Valley Nature Reserve (0.73).

Table 2. Individual accuracy assessment of classified IAPs within the selected nature reserves in 2010

\begin{tabular}{lllll}
\hline \multicolumn{5}{c}{ Producer's accuracy (\%) User's accuracy (\%) } \\
\hline Paradise Valley & Ap & 81 & 98.78 & 0.9817 \\
& Co & 73 & 100 & 1 \\
& Lg & 63 & 81.82 & 0.7273 \\
Roosfontein & Co & 81 & & \\
& Lg & 82 & 100 & 1 \\
\hline
\end{tabular}

Abbreviations: $\mathrm{Ap}=$ Acacia podalyriifolia, $\mathrm{Co}=$ Chromolaena odorata and $\mathrm{Lg}=$ Litsea glutinosa .

Individual user's and producer's accuracies for the 2015 imagery produced similar results to the 2010 imagery in both reserves. The two IAPs, A. podalyriifolia and C. odorata in the Paradise Valley Nature Reserve and C. odorata and L. glutinosa in the Roosfontein Nature Reserve (Table 3) produced accuracies above 70\% (Everitt et al., 2008). Individual Kappa values were excellent ( 0.8 and above) for all species in both reserves besides $C$. odorata in the Roosfontein Nature Reserve (0.6).

Table 3. Individual accuracy assessment of classified IAPs within the selected nature reserves in 2015

\begin{tabular}{|c|c|c|c|c|}
\hline & & Proc & Use & Kappa coefficient \\
\hline \multirow[t]{2}{*}{ Paradise Valley } & $\mathrm{Ap}$ & 100 & 100 & 1 \\
\hline & Co & 100 & 100 & 1 \\
\hline \multirow[t]{2}{*}{ Roosfontein } & Co & 80 & 80 & 0.6 \\
\hline & Lg & 90 & 90 & 0.8 \\
\hline
\end{tabular}

Abbreviation: Ap = Acacia podalyriifolia, $\mathrm{Co}=$ Chromolaena odorata and Lg = Litsea glutinosa .

Figure 2 represents a comparative distribution and density of three selected IAPs between 2010 and 2015. Density of species is represented by intensity of quadrat colour (quadrats with higher colour intensity indicate a higher species density). In 2010 A. podalyriifolia was concentrated towards the centre of the reserve, whereas in 2015 there was a decrease in extent and density of this species. In 2010, C. odorata was found throughout the map, whereas in 
2015 C. odorata density decreased across the map, exhibiting a significant decrease in occurrence and density. The 2010 and 2015 imagery showed L. glutinosa abundantly distributed across both maps with very little to no indication of a decrease in occurrence or density between 2010 and 2015 .

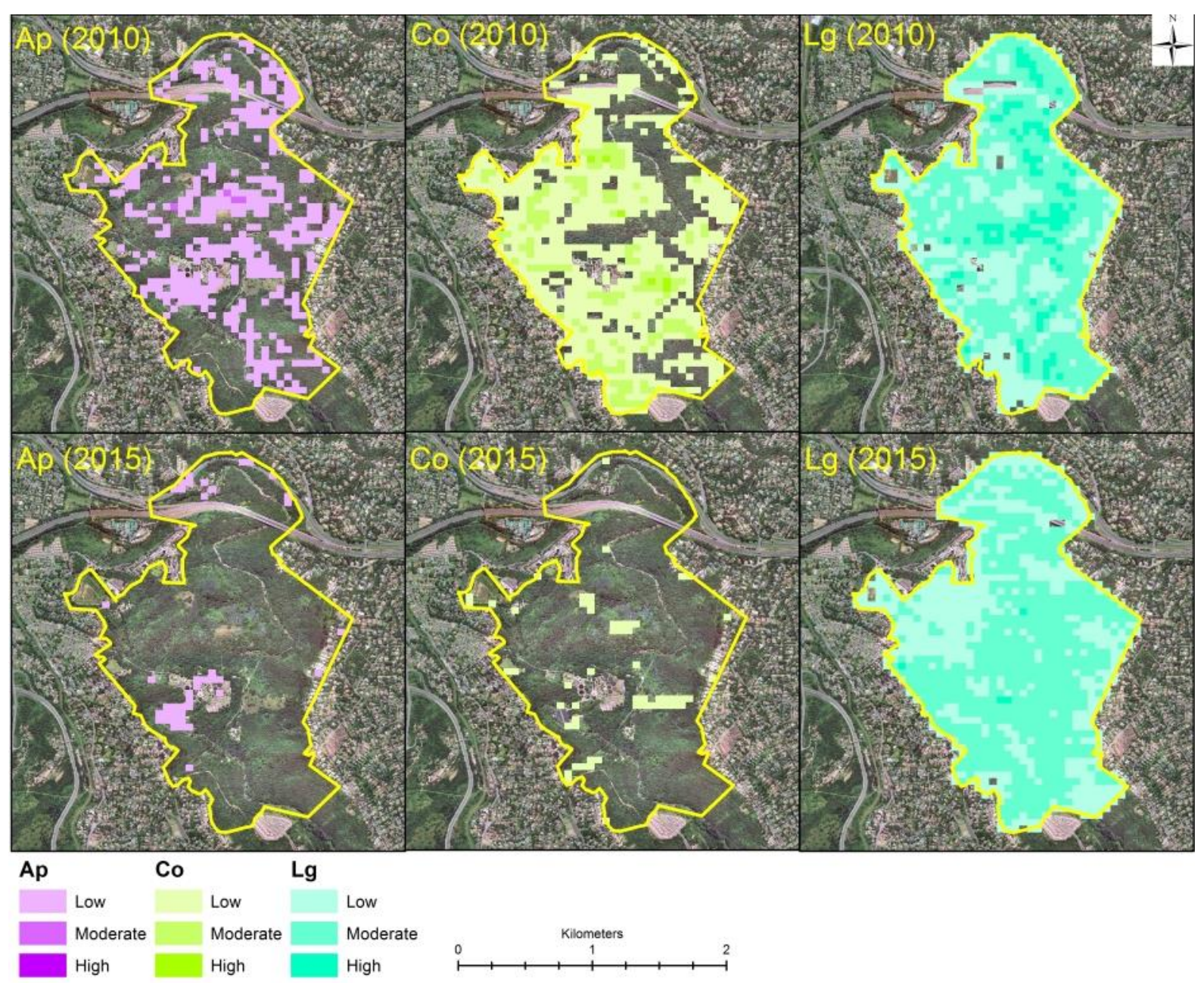

Figure 2. Comparative IAPs distribution maps for 2010 and 2015 in the Paradise Valley Nature Reserve. IAPs $(\mathrm{Ap}=A$. podalyriifolia, $\mathrm{Co}=C$. odorata and $\mathrm{Lg}=L$. glutinosa $)$. Density of species is represented by intensity of quadrat colour, (low $=4-33 \%$, moderate $=34-66 \%$ and high $=67-100 \%)$.

Figure 3 represents the density and distribution of the two selected species in the Roosfontein Nature Reserve between the years of 2010 and 2015. In 2010 C. odorata was spread throughout the reserve, whereas in 2015 there was a significant decrease in its occurrence, with only small isolated patches located in the centre of the reserve. The occurrence of L. glutinosa in 2010 is mainly towards the West and South of the reserve, whereas in 2015 there is a decrease in occurrence and density of the species in the East but a persistent occurrence in the North West of the reserve. 


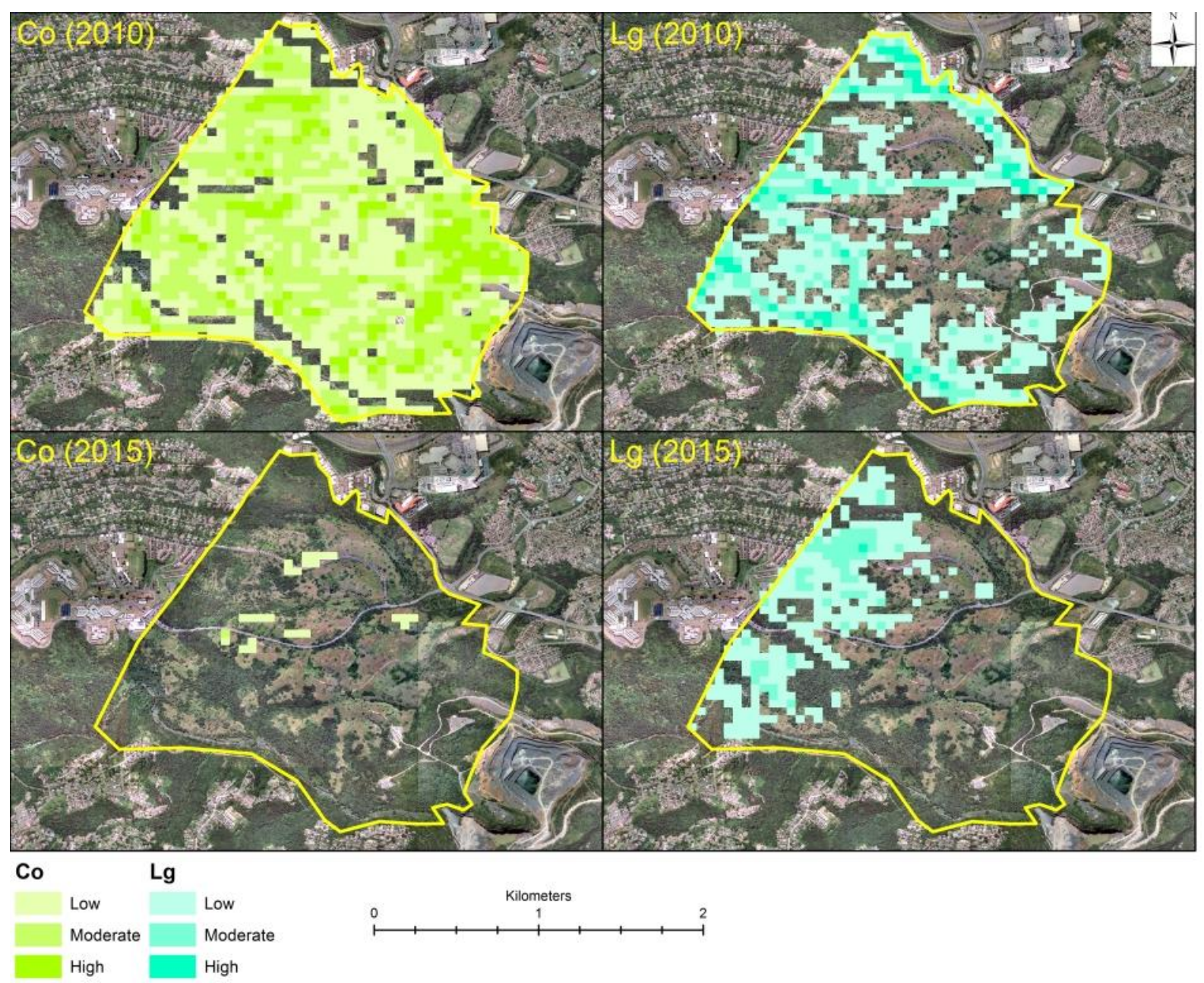

Figure 3. Comparative IAPs distribution maps for 2010 and 2015 in the Roosfontein Nature Reserve IAPs $(\mathrm{Co}=C$. odorata and $\mathrm{Lg}=$ L. glutinosa $)$. Density of species is represented by intensity of quadrat colour, (low $=1-33 \%$, moderate $=34-66 \%$ and high $=67-100 \%$ ).

Table 3 presents the percentage change in hectares (ha) of each species in both reserves. Positive values (+) indicate an increase in area cover of IAPs, while negative values (-) indicate a decrease in area cover. In the Paradise Valley Nature Reserve, A. podalyriifolia and $C$. odorata both showed a high percentage decrease in area cover $(81.6 \%$ and $94.7 \%$ respectively). Litsea glutinosa species also decreased in cover but with a much lower percentage $(8.42 \%)$. In the Roosfontein Nature Reserve, $C$. odorata decreased significantly in cover by $98.9 \%$, while L. glutinosa decreased by $66.4 \%$. 
Table 4. IAP percentage change in area cover between IAPs 2010 and 2015 in the Paradise Valley and the Roosfontein nature reserves

\begin{tabular}{lllll}
\hline & & Area 2010 (ha) & Area 2015 (ha) & Percent change \\
\hline Paradise Valley & Ap & 12.23 & 2.25 & -81.63 \\
& Co & 47.11 & 2.49 & -94.72 \\
& Lg & 129.76 & 118.83 & -8.42 \\
\multirow{3}{*}{ Roosfontein } & & & & \\
& Co & 107.17 & 1.16 & -98.92 \\
& Lg & 39.58 & 13.29 & -66.42 \\
\hline
\end{tabular}

Abbreviations: $\mathrm{Ap}=$ Acacia podalyriifolia, $\mathrm{Co}=$ Chromolaena odorata and $\mathrm{Lg}=$ Litsea glutinosa.

\section{Discussion}

Overall accuracies for the 2010 classified imageries (Table 1) indicate unsuccessful classification results as all were below 85\%. However, the 2015 imageries were classified with good accuracies for both reserves. The detection of the IAP Giant Reed (Aurundo donax) in Texas (United States of America) also had overall accuracies below 85\% (Everitt et al., 2008). The accuracy assessment results of individual species in both 2010 (Table 2) and 2015 (Table 3 ) for both reserves were successful (above 70\%) (Everitt et al., 2008) for all species except $L$. glutinosa (63\%) in the 2010 imagery in the Paradise Valley Nature Reserve which was the lowest classified species. Classification of multispectral imagery can result in high accuracies; however large commission errors may exist due to poor spectral resolution (Rocchini et al., 2015). The successful classification of A. podalyriifolia is due to its leaves exhibiting dense velvety hairs (Henderson, 1995). This surface texture affects the reflection of radiation resulting in a unique spectral signature compared to other vegetation present (Kumar, Schmidt, Dury, \& Skidmore, 2002). Chromolaena odorata has been successfully detected in other studies using WorldView-2 imagery (Malahlela et al., 2015). Litsea glutinosa is noted to occur in heterogeneous stands when compared to the other two selected species (A. podalyriifolia, and $C$. odorata) which form dense monotypic stands and is therefore more difficult to detect (Bradley, 2014). Therefore, hyperspectral imagery could be more suitable for detecting $L$. glutinosa (Rocchini et al., 2015).

The majority of errors produced when conducting field surveys are due to seedlings of the IAPs. Detecting new growth would be difficult. The distribution and density maps facilitate the analysis of change in occurrence and density of the selected IAPs between 2010 and 2015 (van den Berg et al., 2014) which is useful at assessing risk (Joshi et al., 2006). Invasive alien plant density and cover patterns of IAPs are important factors to consider when applying clearing initiatives (Forsyth, Gibson, \& Turner, 2014; van Wilgen et al., 2012) to prioritise for clearing and help assess clearing.

Acacia podalyriifolia, a category $1 \mathrm{~b}$ woody invasive species (NEMBA, 2016), experienced large decreases in percentage cover within the Paradise Valley Nature Reserve. This implies the ongoing clearing programs were successful in this reserve. Furthermore, those pixels that 
were detected as A. podalyriifolia in the 2015 imagery appear to be errors of commission (false positives) (Calviño-Cancela et al., 2014). Even though the clearing of this woody IAPs has been successful in this reserve, their removal could facilitate the recruitment of other IAPs (Loh \& Daehler, 2008).

The shrub species $C$. odorata a category 1b invader (NEMBA, 2016) is indigenous to Central and North America, it has an allelopathic effect which inhibits seedling recruitment of indigenous species (Malahlela et al., 2015). In both the Paradise Valley and the Roosfontein nature reserves, the significant decrease in percentage cover (more than 90\%) is indicative of successful clearing as with A. podalyriifolia in the Paradise Valley Nature Reserve. The clearing of L. glutinosa, a category 1 b tree species (NEMBA, 2016), in the Paradise Valley Nature Reserve, has made little progress, whereas clearing of this species in the Roosfontein Nature Reserve reduced the percentage cover by almost two thirds (66.5\%), and eradicated the species towards the North West of this reserve.

In the Paradise Valley Nature Reserve, the failure in clearing L .glutinosa could have resulted from clearing of other IAPs. Manual clearing can disturb soil and therefore facilitate invasion by other IAPs (Flory \& Clay, 2009). Chemical removal may inhibit the growth of entire functional groups including indigenous species (Flory \& Clay, 2009). Assessment of IAPs removal has been done, but on a national scale and was biome specific (van Wilgen et $a l ., 2012)$ whereas this study assessed clearing on a local scale.

Further research should consider early detection of IAPs as prevention of spread is more cost effective than combating invasion, therefore remote sensing can be applied as an early detection tool to effectively combat invasion (D'Antonio et al., 2004). This can be achieved by the use of Light Detection and Ranging (LiDAR) in conjunction with hyperspectral imagery that will allow for improved IAPs detection and the detection of sub-canopy invaders (Huang $\&$ Asner, 2009). Once a species is established, it is difficult to reduce their spread and to halt invasion. It is easier to deal with areas that are in the initial stages of invasion as there is no seed bank present (Müllerová et al., 2013). The means to detect IAPs in South Africa maybe available, however in addition to the high cost of imagery remote sensing is not a wellestablished field (Mutanga et al., 2009). Furthermore, the South African government has limited resources and battles with a host of issues such as crime, poverty and service delivery, therefore IAPs eradication may not be regarded as a priority. To reduce cost of detection, predictive modelling is suggested for aiding in the removal of potential IAPs (Richardson \& van Wilgen, 2004), as patterns of past invasions can be used to predict future invasion (Bradley \& Mustard, 2006). 


\section{Conclusion}

The aim of this paper was to examine the role of remote sensing in assessing IAPs and their clearing programs within two urban nature reserves (Paradise Valley and Roosfontein), with the goal to assess previous removal programs and facilitate planning towards future removal programs. The user's and producer's classification accuracy of both the 2010 and 2015 imagery in these reserves indicate that only the presence and distribution of L. glutinosa in the Paradise Valley Nature Reserve could not be properly assessed as it was the lowest classified species. Significant decreases in distribution and densities for two IAPs (A. podalyriifolia and C. odorata) in the Paradise Valley Nature Reserve and two IAPs (C. odorata and L. glutinosa) in the Roosfontein Nature Reserve are irrefutable proof of success by the clearing program in relation to these species. While the majority of the results are positive, it is unknown what species have replaced those that have been removed. This study did show that remote sensing is able to assess removal programs, thereby highlighting its use as a tool to aid in monitoring IAP mitigation efforts. Worldview-2 imagery proved successful in detecting target IAPs. However, hyperspectal imagery could improve IAP identification accuracies, including subcanopy species when combined with LiDAR. There is a need to establish routine assessment methods for IAPs removal programs in South Africa. While there has been a significant amount of research in South Africa on IAPs detection using remote sensing, the application of this tool to combat invasion is not very widespread.

\section{Acknowledgements}

Funding for this research was provided by the University of KwaZulu-Natal (UKZN) and the South African National Space Agency (SANSA). Thanks to the Environmental Planning and Climate Protection Department (EPCPD) of the eThekwini Municipality and the Wildlife and Environmental Society of South Africa (WESSA) for allowing access to the study sites and for providing necessary data. The United States Geological Survey (USGS) and SANSA kindly provided imagery.

\section{References}

Africa, S 2016, National environmental managment: Biodiversity act (Act No, 10 of 2004). Goverment Gazette, vol. 66.

Borak, JS 1999, 'Feature selection and land cover classification of a MODIS-like data set for a semiarid environment', International Journal of Remote Sensing, vol. 20, no. 5, pp. 919-938, viewed 9 March 2016, <http://doi.org/10.1080/014311699212993>.

Bradley, BA 2014, 'Remote detection of invasive plants: a review of spectral, textural and phenological approaches', Biological Invasions, vol. 16, no. 7, pp. 1411-1425, viewed 8 September 2015, <http://doi.org/10.1007/s10530-013-0578-9>.

Bradley, BA \& Mustard, JF 2006, 'Characterizing the landscape dynamics of an invasive plant and risk of invasion using remote sensing', Ecological Applications, vol. 6, no. 1, pp. 1132-1147. 
Calviño-Cancela, M., Méndez-Rial, R., Reguera-Salgado, J \& Martín-Herrero, J 2014, 'Alien plant monitoring with ultralight airborne imaging spectroscopy', PloS One, vol.9, no.7, pp. 1-10, viewed 16 October 2015, <http://doi.org/10.1371/journal.pone.0102381>.

Coppin, PR \& Bauer, ME 2009, 'Digital change detection in forest ecosystems with remote sensing imagery', Remote Sensing Reviews, vol. 13, no. 3-4, pp. 207-234, viewed 27 November 2015, <http://doi.org/10.1080/02757259609532305>.

Cuneo, P., Jacobson, CR \& Leishman, MR 2009, 'Landscape-scale detection and mapping of invasive African Olive (Olea europaea L. ssp. cuspidata Wall ex G. Don Ciferri) in SW Sydney, Australia using satellite remote sensing', Applied Vegetation Science, vol. 12, pp. 145-154, viewed 10 May 2016, <http://onlinelibrary.wiley.com/doi/10.1111/j.1654-109X.2009.01010.x/full>.

D'Antonio, CM., Jackson, NE., Horvitz, CC \& Hedberg, R 2004, 'Invasive plants in wildland ecosystems: Merging the study of invasion processes with management needs', Frontiers in Ecology and the Environment, vol. 2, no. 10, pp. 513-521, viewed 6 May 2016, <http://doi.org/10.1890/1540-9295(2004)002[0513:IPIWEM]2.0.CO;2>.

Doody, TM., Lewis, M., Benyon, RG \& Byrne, G 2014, 'A method to map riparian exotic vegetation (Salix spp.) area to inform water resource management', Hydrological Processes, vol. 28, no. 11, pp. 3809-3823, viewed 6 May 2016, <http://doi.org/10.1002/hyp.9916>.

Eck, J., Chainey, S., Cameron, J., Leitner, M \& Wilson, R 2005, Mapping Crime : Understanding Hot Spots. National Institute of Justice, veiwed 4 May 2016, <http://discovery.ucl.ac.uk/11291/1/11291.pdf\nhttp://discovery.ucl.ac.uk/11291/>.

Everitt, JH., Yang, C., Fletcher, R \& Deloach, CJ 2008, 'Comparison of QuickBird and SPOT 5 satellite imagery for mapping giant reed', Journal of Aquatic Plant Management, vol. 46, pp. 77-82.

Flory, SL \& Clay, K 2009, 'Invasive plant removal method determines native plant community responses', Journal of Applied Ecology, vol. 46 no. 2, pp. 434-442, viewed 2 June 2016, <http://doi.org/10.1111/j.1365-2664.2009.01610.x>.

Foody, GM 2002, 'Status of land cover classification accuracy assessment', Remote Sensing of Environment, vol. 80, no.1, pp. 185-201, viewed 4 June 2016, <http://doi.org/10.1016/S00344257(01)00295-4>.

Forsyth, AT., Gibson, LA \& Turner, AA 2014, Assessment of SPOT 6 imagery for mapping the invasive alien plant species Pinus spp. in a mountainous area of the Western Cape. Proceedings of the Second AfricaGEO Conference, 1-12.

Henderson, L 1995, Plant invaders of Southern Africa, Plant Protection Research Institute, Cornell University.

Huang, CY \& Asner, GP 2009, 'Applications of remote sensing to alien invasive plant studies', Sensors, vol. 9, no. 6, pp. 4869-4889, viewed 15 April 2016, < http://doi.org/10.3390/s90604869>.

Johansen, K., Phinn, S., \& Witte, C 2010, 'Mapping of riparian zone attributes using discrete return LiDAR, QuickBird and SPOT-5 imagery: Assessing accuracy and costs', Remote Sensing of Environment, vol. 114, no. 11, pp. 2679-2691, viewed 17 March 2016, <http://doi.org/10.1016/j.rse.2010.06.004>.

Joshi, C., de Leeuw, J., van Andel, J., Skidmore, AK., Lekhak, HD., van Duren, IC \& Norbu, N 2006, 'Indirect remote sensing of a cryptic forest understorey invasive species', Forest Ecology and Management, vol. 225, no. 1-3, pp. 245-256, viewed 5 June 2016, <http://doi.org/10.1016/j.foreco.2006.01.013>.

Kannan, R., Shackleton, CM \& Uma Shaanker, R 2013, 'Reconstructing the history of introduction and spread of the invasive species, Lantana, at three spatial scales in India', Biological Invasions, vol. 15, no. 6, pp. 1287-1302, viewed 7 February 2016, 〈http://doi.org/10.1007/s10530-012-0365-z>.

Kerr, JT \& Ostrovsky, M 2003, From space to species: Ecological applications for remote sensing, 
Trends in Ecology and Evolution, viewed 18 March 2016, <http://doi.org/10.1016/S01695347(03)00071-5>.

Kumar, L., Schmidt, K., Dury, S \& Skidmore, A 2002, Imaging Spectrometry and Vegetation Science. In Imaging spectrometry, pp. 111-156, viewed 15 March 2016, <http://doi.org/10.1007/s13398014-0173-7.2>.

Kumar, Y \& Sahoo, G 2012, Analysis of parametric \& non parametric classifiers for classification technique using WEKA. International Journal of Information Technology and Computer Science, pp. 43-49, viewed 18 November 2015, <http://doi.org/10.5815/ijitcs.2012.07.06>.

Lass, LW., Prather, TS., Glenn, NF., Weber, KT., Mundt, JT \& Pettingill, J 2005, 'A review of remote sensing of invasive weeds and example of the early detection of spotted knapweed (Centaurea maculosa) and babysbreath (Gypsophila paniculata) with a hyperspectral sensor', Weed Science, vol. 53, no. 2, pp. 242-251, viewed 2 October 2015, <http://doi.org/10.1614/WS-04-044R2>.

Le Maitre, DC., van Wilgen, BW., Gelderblom, C., Bailey, C., Chapman, R \& Nel, J 2002, 'Invasive alien trees and water resources in South Africa: case studies of the costs and benefits of management', Forest Ecology and Management, vol. 160, no. 1-3, pp. 143-159, viewed 10 October 2015, <http://doi.org/10.1016/S0378-1127(01)00474-1>.

Loh, RK \& Daehler, CC 2008, 'Influence of woody invader control methods and seed availability on native and invasive species establishment in a Hawaiian forest, Biological Invasions, vol. 10, no. 6, pp. 805-819, viewed 15 October 2015, <http://doi.org/10.1007/s10530-008-9237-y>.

Malahlela, OE., Cho, MA \& Mutanga, O 2015, 'Mapping the occurrence of Chromolaena odorata (L.) in subtropical forest gaps using environmental and remote sensing data', Biological Invasions, vol. 17, no. 7, pp. 2027-2042, viewed 12 June 2016, <http://doi.org/10.1007/s10530-015-0858-7>.

Mas, JF 1999, 'Monitoring land-cover changes: a comparison of change detection techniques' International Journal of Remote Sensing, vol. 20, no. 1, pp. 139-152, viewed 10 May 2016, <http://doi.org/10.1080/014311699213659>.

Miao, X., Patil, R., Heaton, JS \& Tracy, RC 2011, 'Detection and classification of invasive saltcedar through high spatial resolution airborne hyperspectral imagery', International Journal of Remote Sensing, vol. 32, no. 8, pp. 2131-2150, viewed 16 November 2015, <http://doi.org/10.1080/01431161003674618>.

Müllerová, J., Pergl, J \& Pyšek, P 2013, 'Remote sensing as a tool for monitoring plant invasions: Testing the effects of data resolution and image classification approach on the detection of a model plant species Heracleum mantegazzianum (giant hogweed)', International Journal of Applied Earth Observation and Geoinformation, vol. 25, no. 1, pp. 55-65, viewed 10 April 2016, <http://doi.org/10.1016/j.jag.2013.03.004>.

Mutanga, O., van Aardt, J \& Kumar, L 2009, 'Imaging spectroscopy (hyperspectral remote sensing) in southern Africa : an overview', South African Journal of Science, vol. 105, pp. 193-198.

Nagendra, H., Lucas, R., Honrado, JP., Jongman, H R., Tarantino, C., Adamo, M \& Mairota, P 2013, 'Remote sensing for conservation monitoring: Assessing protected areas, habitat extent, habitat condition, species diversity, and threats', Ecological Indicators, vol. 33, pp. 45-59, viewed 7 May 2016, <http://doi.org/10.1017/CBO9781107415324.004>.

Preston-Whyte, RA 1980, Climate of Durban. Natal Town and Regional Planning Reports (Vol. 44), Town and Regional Planning Commission, Durban.

Richardson, DM \& van Wilgen, BW 2004, 'Working for Water: Invasive alien plants in South Africa: how well do we understand the ecological impacts?', South African Journal of Science, vol. 100, pp. 45-52.

Rocchini, D., Andreo, V., Forster, M., Garzon-Lopez, CX., Gutierrez, AP., Gillespie, TW., Neteler, M 2015, 'Potential of remote sensing to predict species invasions: A modelling perspective', Progress in Physical Geography, n.a., pp.1-27, viewed 13 June 2016, 
<http://doi.org/10.1177/0309133315574659>.

Sarma, PK., Lahkar, BP., Ghosh, S., Rabha, A., Das, JP., Nath, NK., Brahma, N 2008, 'Land-use and land-cover change and future implication analysis in Manas National Park, India using multitemporal satellite data', Current Science, vol. 95, no.2, pp. 223-227.

Singh, A 1989, 'Digital change detection techniques using remotely-sensed data', International Journal of Remote Sensing, vol. 10 no.6, pp. 989-1003, viewed 10 December 2015, <http://doi.org/10.1080/01431168908903939>.

Stuckenberg, T., Münch, Z \& van Niekerk, A 2014, 'Multi-temporal remote sensing land-cover change detection for biodiversity assessment in the Berg River catchment', South African Journal of Geomatics, vol. 2, no. 3, pp. 189-205, viewed 18 Febrruary 2016, <http://www.ajol.info/index.php/sajg/article/view/106977>.

Underwood, EC., Ustin, SL \& DiPietro, D 2003, 'Mapping nonnative plants using hyperspectral imagery', Remote Sensing of Environment, vol. 86, no. 2, pp. 150-161, viewed 20 January 2016, <http://doi.org/10.1016/S0034-4257(03)00096-8>.

van den Berg, E., Kotze, I \& Beukes, H 2014, 'Detection, quantification and monitoring of Prosopis in the Northern Cape Province of South Africa using remote sensing and GIS', South African Journal of Geomatics, vol. 2, no. 2, pp. 68-81, viewed 22 September 2015, <http://www.ajol.info/index.php/sajg/article/view/106983>.

van Wilgen, BW., Forsyth, GG., Le Maitre, DC., Wannenburgh, A., Kotzé, JDF., van den Berg, E \& Henderson, L 2012, 'An assessment of the effectiveness of a large, national-scale invasive alien plant control strategy in South Africa', Biological Conservation, vol. 148, no. 1, pp. 28-38, viewed 15 August 2016, <http://doi.org/10.1016/j.biocon.2011.12.035>.

Vieira, R., Finn, JT \& Bradley, BA 2014, 'How does the landscape context of occurrence data influence models of invasion risk? A comparison of independent datasets in Massachusetts, USA', Landscape Ecology, vol. 29, pp. 1601-1612, viewed 18 March 2016, <http://doi.org/10.1007/s10980-014-0080-5>.

Vilà, M., Basnou, C., Pyšek, P., Josefsson, M., Genovesi, P., Gollasch, S \& Hulme, PE 2010, 'How well do we understand the impacts of alien species on ecosystem services? A pan-European, cross-taxa assessment', Frontiers in Ecology and the Environment, vol. 8, no. 3, pp. 135-144, viewed 8 July 2016, <http://doi.org/10.1890/080083>.

Zhang, Y \& Mishra, R 2012, 'A review and comparison of commercially available pan-sharpening techniques for high resolution satellite image fusion', Geoscience and Remote Sensing Symposium. pp. 182-185, viewed 3 August 2015, <http://doi.org/10.1109/IGARSS.2012.6351607>. 